\title{
BMJ Open Municipal contraceptive services, socioeconomic status and teenage pregnancy in Finland: a longitudinal study
}

\author{
Eerika Jalanko (D) , ${ }^{1,2}$ Frida Gyllenberg, ${ }^{2,3}$ Nikolas Krstic, ${ }^{4}$ Mika Gissler, ${ }^{5}$ \\ Oskari Heikinheimo ${ }^{1,2}$
}

To cite: Jalanko E, Gyllenberg F, Krstic N, et al. Municipal contraceptive services, socioeconomic status and teenage pregnancy in Finland: a longitudinal study. BMJ Open 2021;11:e043092. doi:10.1136/ bmjopen-2020-043092

- Prepublication history for this paper is available online. To view these files, please visit the journal online (http://dx.doi org/10.1136/bmjopen-2020043092).

Received 28 July 2020 Revised 14 December 2020 Accepted 24 January 2021

\section{Check for updates}

(C) Author(s) (or their employer(s)) 2021. Re-use permitted under CC BY-NC. No commercial re-use. See rights and permissions. Published by BMJ.

${ }^{1}$ Obstetrics and Gynecology, Naistenklinikka, Helsinki, Finland ${ }^{2}$ Faculty of Medicine, University of Helsinki, Helsinki, Finland ${ }^{3}$ City of Vantaa, Division of Health Care and Social Services, Vantaa, Finland

${ }^{4}$ The University of British Columbia, Vancouver, British Columbia, Canada

${ }^{5}$ Information, Finnish Institute for Health and Welfare, Helsinki, Finland

Correspondence to Dr Oskari Heikinheimo; oskari.heikinheimo@helsinki.fi

\section{ABSTRACT}

Objectives Declining teenage pregnancy rates have been linked to improved access to youth-friendly contraceptive services, but information on the combined association of these services and socioeconomic factors with teenage pregnancy is lacking.

Design and setting This retrospective longitudinal register-based study covers the annual teenage childbirth and induced abortion rates in the 100 largest municipalities in Finland in 2000-2018. We investigated the combined association of regional, socioeconomic (ie, education level and need for social assistance) and adolescent contraceptive service variables (ie, free-ofcharge contraception, an adolescent-only clinic and availability of over-the-counter emergency contraception (OTC EC)) with teenage childbirth and induced abortion rates at the municipality level by using Poisson mixedeffects model.

Primary outcome measures Annual teenage childbirth and induced abortion rates as numbers per 1000 teenage girls aged $15-19$ years old in the 100 largest municipalities in Finland from 2000 to 2018.

Results The following variables were significantly associated with both lower teenage childbirth and induced abortion rates when adjusted for all the other variables used in the model: providing free-of-charge contraception (rate ratio (RR) $0.82(95 \% \mathrm{Cl} 0.73$ to 0.92$)$ and $\mathrm{RR} 0.87$ (95\% $\mathrm{Cl} 0.79$ to 0.96 ), respectively), availability of OTC EC without age limit (RR 0.70 (95\% $\mathrm{Cl} 0.67$ to 0.75$)$ and RR 0.74 (95\% Cl 0.71 to 0.78 ), respectively), and high education level of the municipality (RR 0.94 (95\% Cl 0.94 to 0.95 ) and RR 0.94 (95\% Cl 0.93 to 0.94), respectively). Conclusion Providing free-of-charge contraception and availability of OTC EC without age limit are associated with lower teenage pregnancy rates. These services combined with proper counselling are thus important contents of youth-friendly contraceptive services that should be provided equally for all teenagers in order to further reduce teenage pregnancy rates.

\section{INTRODUCTION}

Teenage pregnancy rates have been declining in Europe and in the USA for over a decade, although rates of both teenage childbirth and induced abortion vary by country. ${ }^{1-3}$ Childbearing in adolescence is associated with adverse obstetrical outcomes, ${ }^{4}$ as well as

\section{Strengths and limitations of this study}

- We investigated the association of health service and socioeconomic variables to annual teenageinduced abortion and childbirth rates simultaneously in the same study setting from 2000 to 2018.

- The data, based on the reliable Finnish health registers, cover practically all teenage pregnancies of the 100 largest municipalities in Finland.

- The information on the availability of free-of-charge contraception and adolescent clinics was obtained from the questionnaire to the municipalities, and might thus be exposed to erroneous responses.

with socioeconomic and educational disadvantages. ${ }^{56}$ Especially repeated teen births in the US cluster in counties with lower socioeconomic conditions. ${ }^{5}$ Furthermore, women with a history of teenage pregnancy face an increased risk for psychiatric morbidity later in life. ${ }^{67}$ As teenage pregnancy causes significant challenges at both the individual and the societal level, it is crucial to understand the factors associated with declining teenage pregnancy rates.

The downward trend in teenage pregnancy rates has mainly been linked to increased use of contraception, ${ }^{2} 38$ especially that of long-acting reversible contraceptives (LARC) - that is, intrauterine devices (IUDs) and implants. ${ }^{29}$ Further, the availability of accessible and/or affordable contraceptive services have been found to increase the use of contraception among adolescents and decrease teenage pregnancies. ${ }^{1011}$

Providing free-of-charge contraceptives removes the financial barrier to contraception and associates with lower teenage pregnancy rates. ${ }^{11}{ }^{12}$ Specifically, offering free-of-charge LARC methods has been identified as an effective approach to prevent teenage pregnancy. ${ }^{12} 13$ In addition to reducing financial barriers, providing comprehensive sexuality education and counselling on contraception 
has been shown to increase adolescents' contraceptive use. $^{101415}$ Moreover, expanding contraceptive services outside the clinical setting, for example, by providing contraceptive methods over-the-counter (OTC), might potentially decrease the rate of teenage pregnancy. ${ }^{16} 17$ However, providing OTC emergency contraception (EC) has not been shown to affect adolescent pregnancy rates. ${ }^{1819}$

Despite these observations, it is crucial to take into account the socioeconomic conditions when investigating the association of contraceptive services on teenage pregnancies and vice versa. However, studies examining the combined effects of both socioeconomic status and contraceptive services on teenage pregnancy rates are lacking. In Finland, the municipalities are obligated to offer family planning services for all citizens since $1972 .{ }^{20}$ However, it is not specified where and how the services should be arranged. Therefore, access to contraceptive services, as well as the content of the services differs between municipalities. In this study, we used information on how the contraceptive services are arranged together with information from Finland's reliable health registers, ${ }^{21}$ to analyse the combined effect of contraceptive service models and the socioeconomic profile of the municipalities, on the teenage pregnancy rates in the population. Specifically, our aim was to identify to what extent certain socioeconomic factors and features of contraceptive services associate with teenage pregnancy rates at the municipality level.

\section{METHODS}

In this longitudinal register-based study, we investigated the association of region, educational level and socioeconomic status of the municipalities, and variables on contraceptive service provision with the annual teenage birth and induced abortion rates of the 100 largest municipalities in Finland, from 2000 to 2018. Hence, the data encompasses 1900 measurement points across the follow-up.

In 2018, there were 311 municipalities in Finland. The total population in Finland was 5.5 million, and most of the municipalities are sparsely populated. We included the 100 largest municipalities based on the population in 2018 in this study. We considered all municipal mergers from 2000 through 2018, and the annual municipal division corresponds to that in 2018. The population in these municipalities ranged from 9862 to 648042 with a total of 4631980 , and accounted for $84 \%$ of the total population in 2018.

\section{Outcomes}

Our primary outcomes were the annual rates of teenage childbirth and induced abortion in each of the 100 municipalities between 2000 and 2018. We defined teenager as being aged 15-19 years at the time of childbirth or induced abortion. We calculated the crude annual rates of childbirth and abortion as counts per 1000 women aged 15-19 years in the given municipality.

Data on childbirths and induced abortions were obtained from the Medical Birth Register and the Register of Induced Abortions, maintained by the Finnish Institute for Health and Welfare. The Medical Birth Register was established in 1987 and contains all livebirths and stillbirths with gestational age at least 22 weeks or infant weight at least $500 \mathrm{~g}$ at the time of delivery, as well as data on mothers. The Register of Induced Abortions, available in electronic format since 1983, covers all induced abortions. Reporting to these registers is mandatory by law, and the accuracy of both registers is well validated. ${ }^{21} 22$ However, these registers do not include miscarriages, that is, pregnancies ending spontaneously before gestational weeks 22, or ectopic pregnancies. Hence, these pregnancies were not included in the study.

\section{Explanatory variables}

We assessed regional, socioeconomic and contraceptive service variables to examine the association with teenage pregnancy rates. The prevalence of the explanatory variables aggregated into four major regions are shown in table 1 .

To visualise the change in teenage birth and abortion rates across follow-up, we aggregated the municipalities into larger areas based on the five major regions in Finland: Helsinki-Uusimaa (Capital region), Southern Finland, Western Finland, Åland and Northern and Eastern Finland. However, Åland has only one municipality among the 100 municipalities included in the study, and was thus combined with Southern Finland, which is geographically closest to Åland. There were 16 municipalities in the Helsinki-Uusimaa region (population of 1616203 in 2018), 24 in Southern Finland and Åland (974 141), 33 in Western Finland (1 107 930) and 27 in Northern and Eastern Finland (933 706). This regional division also describes the urbanisation in different parts of Finland. The degree of urbanisation refers to the proportion of people living in urban settlements among the population in the region. The degree of urbanisation in 2018 in Helsinki-Uusimaa was 96.4\%, in Southern Finland and Åland $90.7 \%$, in Western Finland $89.1 \%$, and in Northern and Eastern Finland 86.4\%.

To describe the socioeconomic status of the residents in the municipalities, we used the percentage of adults receiving social assistance in each municipality, and the percentage of citizens with a high education level, that is either a university, a polytechnic degree, or studies of more than 3 years in a vocational institution. We obtained data on social assistance recipients from the Finnish Institute for Health and Welfare, and data on educational level from Statistics Finland.

To examine the association between contraceptive services and teenage pregnancy rates we used the following variables: availability for OTC EC, municipal contraceptive services for adolescents centralised to an adolescent clinic and possibility to receive any method of 
Table 1 Prevalence of the explanatory variables in the study municipalities aggregated into four major regions

\begin{tabular}{|c|c|c|c|c|c|}
\hline & Helsinki-Uusimaa & $\begin{array}{l}\text { Southern } \\
\text { Finland and } \\
\text { Åland }\end{array}$ & $\begin{array}{l}\text { Western } \\
\text { Finland }\end{array}$ & $\begin{array}{l}\text { Eastern and } \\
\text { Northern } \\
\text { Finland }\end{array}$ & $\begin{array}{l}\text { All } \\
\text { municipalities }\end{array}$ \\
\hline \multicolumn{6}{|l|}{ Socioeconomic variables $(\% \pm \mathrm{SD})^{\star}$} \\
\hline Social assistance recipients & $6.1 \pm 1.8$ & $6.1 \pm 1.9$ & $5.8 \pm 1.8$ & $7.1 \pm 2.1$ & $6.3 \pm 2.0$ \\
\hline Citizens with high education level & $30.0 \pm 5.9$ & $25.1 \pm 4.4$ & $24.4 \pm 5.9$ & $23.5 \pm 5.3$ & $25.2 \pm 5.8$ \\
\hline \multicolumn{6}{|l|}{ Contraceptive service variables $†$} \\
\hline OTC EC for all ages & $16(64)$ & $24(96)$ & $33(132)$ & 27 (108) & $100(400)$ \\
\hline $\begin{array}{l}\text { Contraceptive services centralised to an } \\
\text { adolescent clinic }\end{array}$ & $1(19)$ & $4(61)$ & $1(19)$ & $1(10)$ & 7 (109) \\
\hline $\begin{array}{l}\text { Free-of-charge contraception until the age } \\
\text { of } 20 \text { or } 25\end{array}$ & $4(5)$ & $2(11)$ & $9(20)$ & $10(30)$ & $25(66)$ \\
\hline
\end{tabular}

*Mean percentage $( \pm$ SD) across the follow-up from 2000 to 2018.

†Number of municipalities offering the service, and number of municipalities offering the service together with the total number of years with the service available in parenthesis.

OTC EC, over-the-counter emergency contraception.

contraception except condoms free of charge until the age of 20 or 25 . OTC EC became available in all pharmacies in Finland for over 15-year-olds in 2002 and without age restrictions in 2015 .

To obtain information on how the contraceptive services were provided, we performed a questionnaire to the municipalities concerning centralisation of adolescent contraceptive services and availability of free-ofcharge contraception, and when the services had become available. The questionnaire was directed to the physicians responsible for the contraceptive services in each municipality. All 100 municipalities responded the questionnaire either by email or by phone. We received $20 \%$ of the responses from the first survey round conducted by email. The second email round increased the response rate to $60 \%$, and the remaining responses we obtained by phone.

Contraceptive services are mainly arranged in health centres, family planning clinics and/or school healthcare, but the initiation years of these services were not available in the responses. However, in seven municipalities, the contraception services for adolescents were centralised to an adolescent clinic, and the initiation years of the clinics were available from the responses.

During 2000-2018, all municipalities offered at least a 3-month supply of contraceptive pills free of charge to women initiating contraception. Altogether 25 municipalities offered all contraception free of charge until the age of 20 or 25, including pills, patches, vaginal rings, hormonal IUDs, copper IUDs and implants. The state of adolescent clinics and free-of-charge contraception varied between the municipalities, but all municipalities offering these services continued them at least until the end of 2018, and there were no breaks in the services during the follow-up.
High education level and need for social assistance in the municipalities were treated as continuous variables (percentages on the unit scale), major region as a nominal variable (values 1 to 4 according to the major region), and OTC EC, adolescent clinic and free-ofcharge contraception as binary variables (values 0 or 1 ). Binary variables were defined as having the value zero at measurement points where and when the service was not available, and the value one where and when the service was available. OTC EC was represented by two variables, each representing the policy implemented in 2002 for over 15 years old and in 2015 for everyone without an age restriction.

\section{Statistical methods}

To analyse the relationships between the explanatory variables and teenage childbirth and abortion rates, we used Poisson mixed effects models with the log of the female population aged 15-19years old in each municipality per 1000 as offset.

Initially, we had obtained several socioeconomic variables from the registers of Statistics Finland, and we used a combination of the variance inflation factor (VIF), the Akaike information criterion (AIC) and avoidance of non-convergent models, to select which socioeconomic variables to include in the model of teenage births. We used the AIC measure during forward model selection for socioeconomic variables, but included variables on contraceptive services and regional variables in our initial model, since these were our primary variables of interest. If the inclusion of a variable resulted in the greatest reduction in AIC compared with any other variable outside of the model, then we would attempt to include the variable. However, due to potential non-convergence of the model, likely because of multicollinearity or increased 
model complexity, we would select the variable that resulted in the greatest reduction in AIC while preserving convergence of the model. We repeated this process until any further inclusion of variables did not reduce the AIC. Subsequently, we examined the VIF values of all variables to assess the level of multicollinearity present within the model. This selection procedure was used for modelling teenage births, while the same variables were included in the model of teenage induced abortions, to allow for direct comparisons. The model for teenage induced abortions did successfully converge. Furthermore, the VIFs in both models remained below 3 (values between 1 and 2.6), which is evidence of minimal to low multicollinearity impacting our model, and thus, no factors were removed from the model. In addition to the final models, we also conducted univariate analyses for each variable included within the model without adjusting for other variables.

We present the results as rate ratios (RRs) with $95 \%$ CIs to assess the effect of each variable to the change in teenage birth and induced abortion rates by using comparisons appropriate for each variable. For regional variables the largest region of Helsinki-Uusimaa served as a reference level. For socioeconomic variables (ie, the percentage of citizens with high education level and percentage of adults receiving social assistance) the RRs present the change in abortion and birth rates in relation to each percent unit increase in high education level or social assistance. For contraceptive service variables (ie, OTC EC, contraception services centralised to an adolescent clinic and free-of-charge contraception until the age of 20 or 25) the RRs present the change in birth and abortion rates compared with the years and municipalities where the service was not available. Statistical significance of coefficient estimates within the model was determined using a significance level of $5 \%$.

All analyses were conducted using R V.3.5.1 (R Core Team (2018). R: A language and environment for statistical computing. R Foundation for Statistical Computing, Vienna, Austria. URL https://www.R-project.org/) and GraphPad Prism V.8.4.2 (GraphPad Software, San Diego, California USA, www.graphpad.com.)

\section{Patient and public involvement}

No patient involved.

\section{RESULTS}

There were altogether 20544 teenage childbirths and 30 696 teenage induced abortions in the 100 municipalities in the years 2000 to 2018. Figure 1 shows the aggregated rates of annual unadjusted teenage childbirth and induced abortion in the four major regions during the follow-up. Both childbirth and induced abortion rates decreased in all regions over time. The childbirth rates were highest in
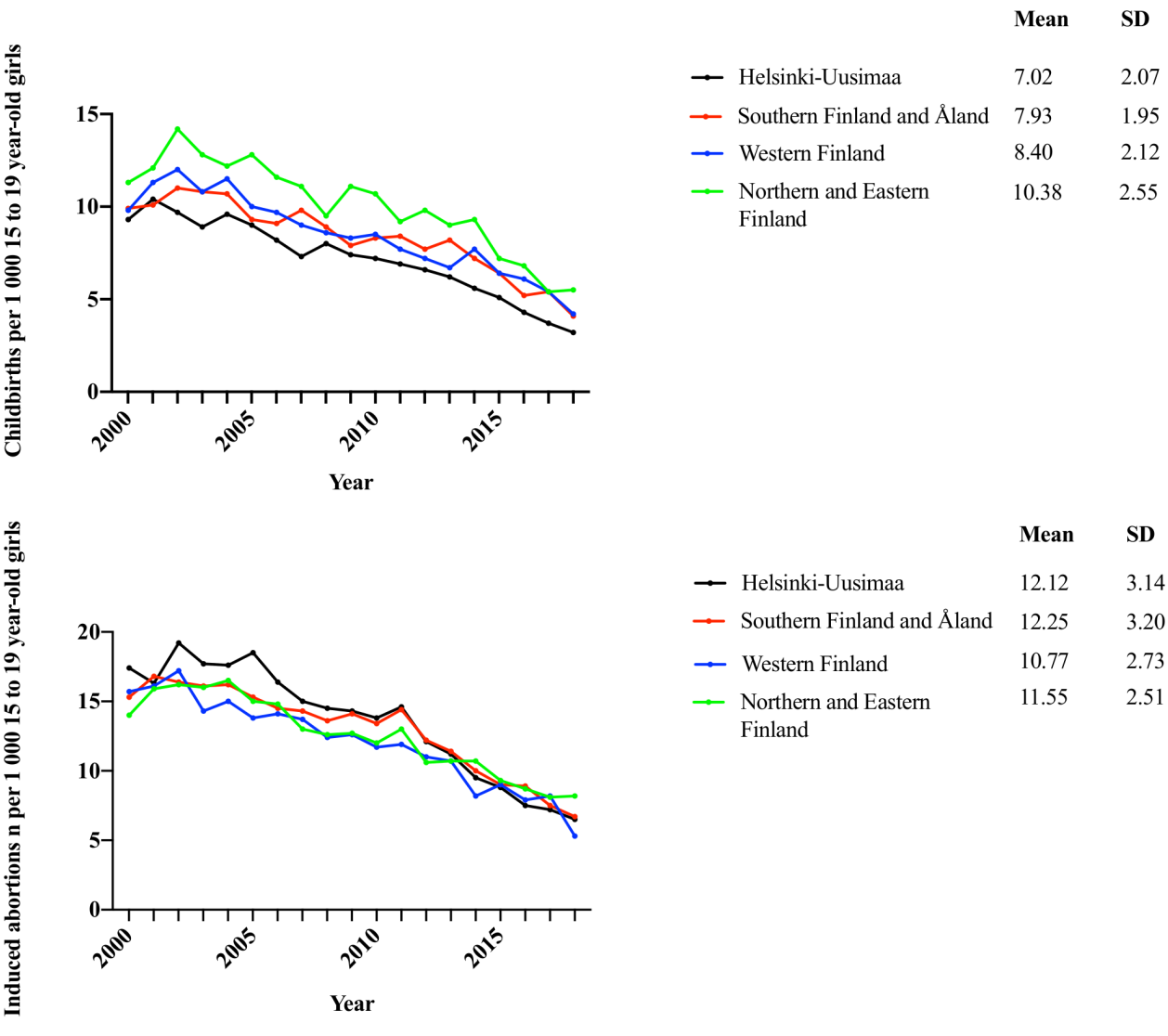

$\mathrm{SD}=$ standard deviation

Figure 1 Unadjusted teenage childbirth and induced abortion rates across the follow-up from 2000 to 2018 based on the major regions in Finland. 

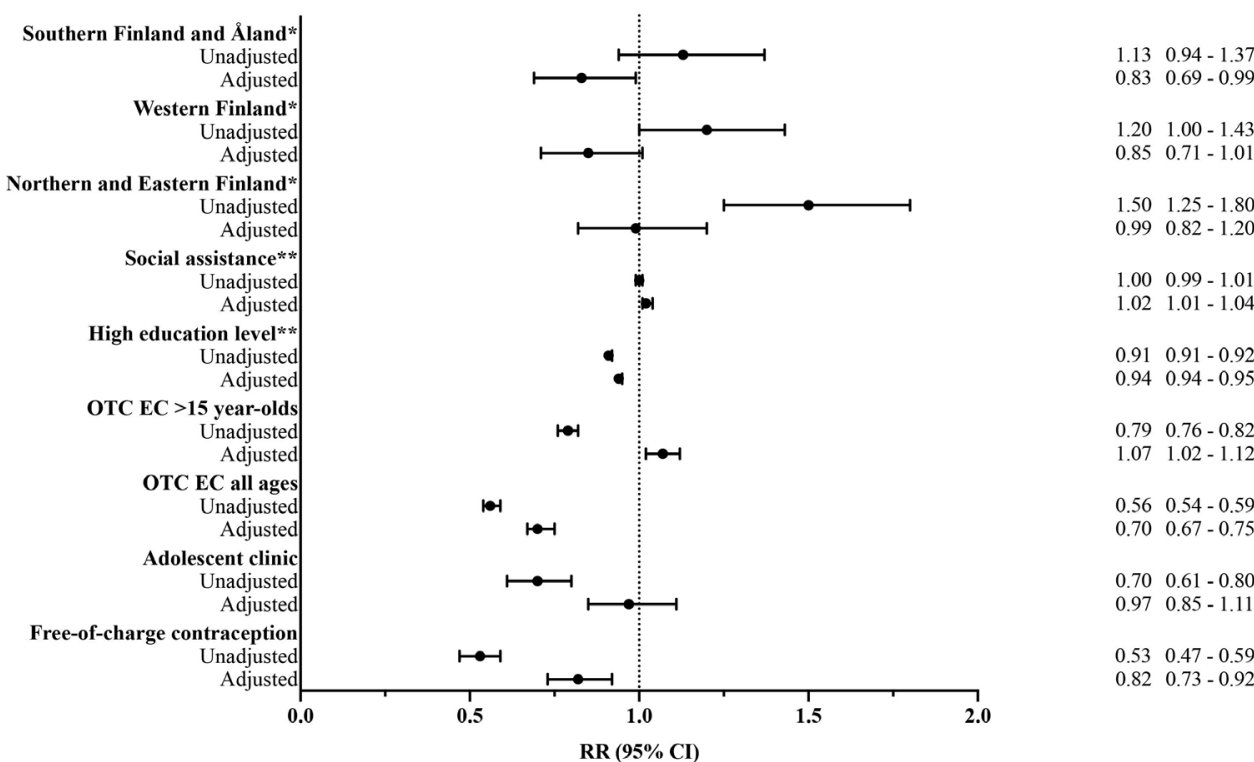

Figure 2 Unadjusted and adjusted rate ratios of variables for teenage childbirths. ${ }^{*}$ Compared with the Helsinki-Uusimaa major region. ${ }^{* *}$ Compared with $1 \%$ unit increase in social assistance recipients or citizens with high education level. OTC EC, overthe-counter emergency contraception; RR, rate ratio.

Northern and Eastern Finland throughout the follow-up, whereas the lowest birth rates were detected in the most densely populated region Helsinki-Uusimaa. By contrast, the induced abortion rates were higher in HelsinkiUusimaa between 2002 and 2011 when compared with the other major regions, but thereafter the differences between the regions disappeared (figure 1).

Helsinki-Uusimaa was the most densely populated major region with total population of 1616203 in 16 municipalities. The highest mean percentage of adults receiving social assistance was seen in Northern and Eastern Finland, as well as the lowest percentage of citizens with high education level. Contraceptive services were most often centralised to an adolescent clinic in Western Finland, whereas free-of-charge contraception was offered most commonly in Northern and Eastern Finland. The policies of being able to purchase OTC EC came into effect at the same time in each municipality: in 2002 for over 15 years olds and in 2015 for all ages.

The unadjusted and adjusted RRs from the mixedeffects Poisson regression model for teenage childbirths and induced abortions are presented in figures 2 and 3, respectively, showing the association between different variables and teenage pregnancy rates. The following variables were associated significantly with lower teenage childbirth rates after adjustment: major region Southern Finland and Åland (RR $0.83,95 \%$ CI 0.69 to 0.99 ), high education level of the municipality (RR $0.94,95 \%$ CI 0.94 to 0.95 ), availability of OTC EC for all ages (RR 0.70, $95 \% \mathrm{CI} 0.67$ to 0.75$)$ and providing free-of-charge contraception (RR $0.82,95 \%$ CI 0.73 to 0.92 ).

For teenage induced abortions, the following variables were associated significantly with lower abortion rates after adjustment: major regions Southern Finland and
Åland (RR 0.73, 95\% CI 0.57 to 0.93), Western Finland (RR 0.60, 95\% CI 0.48 to 0.76 ) and Northern and Eastern Finland (RR $0.62,95 \%$ CI 0.49 to 0.79 ), high education level of the municipality (RR $0.94,95 \%$ CI 0.93 to 0.94 ), availability of OTC EC for all ages (RR $0.74,95 \%$ CI 0.71 to 0.78 ) and providing free-of-charge contraception (RR $0.87,95 \%$ CI 0.79 to 0.96 ).

However, the centralisation of contraception services to an adolescent clinic did not associate significantly with either teenage childbirths or teenage induced abortions after adjustment (figures 2 and 3). Additionally, the unadjusted RRs for availability of OTC EC for over 15 years old were lower than 1 for both teenage childbirths and induced abortions, whereas the adjusted RRs were greater than 1 (figures 2 and 3). We further investigated this change by adding one variable at a time, and found the shift to occur after adjustment for high education level.

\section{DISCUSSION}

In this study observing regional, and municipal socioeconomic and contraceptive service variables simultaneously in the 100 largest municipalities in Finland, we found that high education level of the municipality and providing free-of-charge contraception were associated with lower rates of both teenage childbirth and induced abortion. While providing OTC EC only for girls older than 15 did not associate with a reduction in teenage pregnancy rates, OTC EC for all was associated with a significant reduction in both childbirth and induced abortion rates. However, we did not find a significant association between centralising contraception services to an adolescent clinic and either the rate of teenage childbirths or that of induced abortions. 


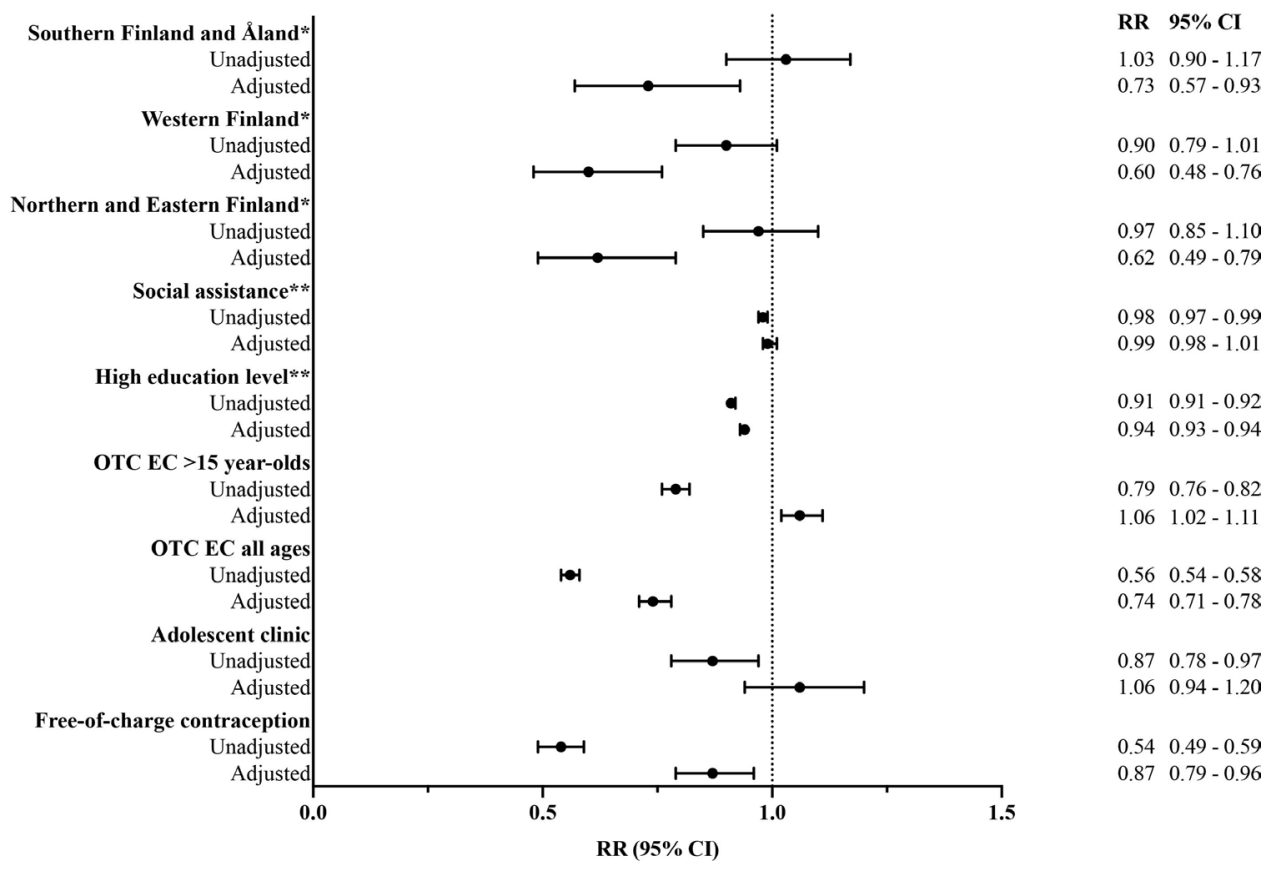

Figure 3 Unadjusted and adjusted rate ratios of variables for teenage induced abortions. *Compared with the HelsinkiUusimaa major region. ${ }^{*}$ Compared with $1 \%$ unit increase in social assistance recipients or citizens with high education level. OTC EC, over-the-counter emergency contraception; RR, rate ratio.

Our results on variables associated with lower teenage pregnancy rates (ie, high education level, providing free-of-charge contraception and OTC EC for all ages) are in agreement with previous literature, except for the OTC EC. Two studies from the USA and UK did not find a significant association between increased number of teenage conceptions and availability of OTC EC..$^{18} 19$ However, at the time of these studies, the only available OTC EC pill was that of levonorgestrel. Conversely, at the time of our present study, the other approved oral medication for EC, ulipristal acetate, also became available without prescription in each municipality in 2015 . The age limit for OTC EC was removed in the same year. Ulipristal acetate is significantly more effective than levonorgestrel in preventing pregnancies even if taken 5 days after unprotected intercourse. ${ }^{23}{ }^{24}$ This might explain in part our finding that OTC EC for all ages associated with both lower rates of teenage childbirth and induced abortion. Furthermore, the use of hormonal contraception is typically lower among younger teenagers, ${ }^{2}$ and therefore, OTC EC might have a more important role among teenagers under the age of 15 than for older teenagers in preventing unintended pregnancies.

Concerning other contraceptive services, our findings are in line with previous studies that offering freeof-charge contraception associates with lower rates of teenage childbirth and induced abortion. ${ }^{11}{ }^{13}$ Although LARC methods have been shown to be the most effective contraceptives in preventing teenage pregnancies, ${ }^{9}$ our results support also the efficacy of offering both LARC and short-acting reversible contraceptive (SARC) methods at no cost for teenagers. However, proper information of different contraceptive options is needed so that each teenager can choose the most suitable and effective method to use. Accordingly, in previous studies adolescents have been reported to prefer counselling with clear information about risks and benefits of contraception. ${ }^{25}{ }^{26}$ Although proper counselling is ensured in adolescent clinics we found no significant association between centralising contraceptive services to an adolescent clinic and lowering teenage pregnancy rates. This might be due to the fact that there were only seven municipalities offering contraceptive services in a centralised adolescent clinic in our data. In addition, it has been shown that teenagers find convenient location and flexible operating hours as important factors for contraceptive services. ${ }^{27}$ Specifically, offering contraceptive services within school healthcare has been shown to increase the use of contraception among adolescents. ${ }^{10}$ Thus, convenient location and flexible operating hours might play a more remarkable role for teenagers seeking contraceptive services than a specialised adolescent clinic.

Furthermore, as low socioeconomic status has been shown to associate with higher teenage pregnancy rates in several previous studies, and thus easy access to low-cost or no-cost contraceptive services for adolescents might be especially important in areas with lower socioeconomic status. ${ }^{56}$ Our results support these findings especially for the association between high education level and both lower teenage childbirth and induced abortion rates (figures 2 and 3). Specifically, the teenage childbirth rates were highest in Northern and Eastern Finland, where the education level is lowest and the percentage of social assistance recipients is highest (figure 1, table 1). However, the adjusted induced abortion rates were significantly lower in the other major regions compared 
with Helsinki-Uusimaa suggesting that other factors not examined in this study (eg, access to abortion services due to longer distances or less favourable attitude towards induced abortion) might explain the differences between the major regions. Furthermore, the average age of firsttime mothers in Finland has been highest in the capital Helsinki for over three decades being 31.5 years in $2018 .^{28}$ In contrast, the average age of first-time mothers in Northern Finland, where the degree of urbanisation is lowest, was 28.0 years in $2018 .^{28}$ This was reflected also in our finding of highest teenage childbirth rate in the Northern and Eastern Finland, both with lower than average degree of urbanisation.

The major strength of our nationwide study is that we examined the association of socioeconomic and contraceptive service related variables to teenage pregnancy rates simultaneously in the same study setting at the municipality level. The data relies on reliable and validated Finnish health registers covering practically all teenage childbirths and induced abortions in each municipality. ${ }^{21}{ }^{22}$ We analysed the data annually during a long time period, from 2000 to 2018, spanning 1900 measurement points. Additionally, the data consists of the 100 largest municipalities in Finland covering $84 \%$ of the total population.

We acknowledge the following limitations of our study. Although we examined the association of several variables with declining teenage pregnancy rates there are other possible factors as well that might have affected to the lowering rates of both teenage induced abortions and childbirths. For instance, adolescent sexual behaviour and substance use might have changed across the follow-up. However, we were not able to investigate the possible association of these variables with the teenage pregnancy rates. Furthermore, all data are on the municipal level, and thus we lack information of the socioeconomic status of the individuals. However, variables of socioeconomic status are not available for teenagers, and hence these aggregated data provide a proxy for their socioeconomic status. Another limitation is that the registers lack information about the intentionality of the pregnancies. However, the majority of the adolescent pregnancies are reported to be unintended, as shown by Wellings et al from the UK in $2013 .{ }^{29}$ In fact, the study found that $88 \%$ of 16-19year-old adolescents with a history of pregnancy identified it as unplanned or ambitious. ${ }^{29}$ In addition, the questionnaire to the municipalities was the only source of information on the availability of free-of-charge contraception and adolescent clinics, and these data might thus be susceptible to erroneous responses.

We conclude that providing free-of-charge contraception, both SARC and LARC methods, as well as OTC EC without age limit are associated with lower rates of both teenage childbirth and induced abortion at the municipality level. In order to reduce teenage pregnancy, healthcare providers and policy-makers should ensure provision of free-of-charge contraception combined with proper counselling and convenient access to high-quality contraceptive services for all adolescents regardless of their residential area or socioeconomic background. In future research, it would be important to examine how youth-friendly contraceptive services affect the usage of different contraceptive methods in a population level, and how it associates with teenage pregnancy rates.

Acknowledgements We would like to thank all the 100 municipalities that responded to the questionnaire, and study nurse Pirjo lkonen for helping with the collection of questionnaire response data.

Contributors EJ, FG, MG and $\mathrm{OH}$ designed the study approach. EJ and MG acquired the data, and EJ harmonised it. NK analysed the data, and EJ, NK and FG interpreted the results. EJ produced the figures and drafted the manuscript. FG, $\mathrm{NK}, \mathrm{MG}$ and $\mathrm{OH}$ critically revised the manuscript. All authors approved the final manuscript.

Funding Juho Vainio Foundation (grant number 202010112) and The Hospital district of Helsinki and Uusimaa. Open access funded by Helsinki University Library.

Disclaimer The funders had no role in study design, data collection and analysis, preparation of the manuscript, or decision to publish.

Competing interests None declared.

Patient consent for publication Not required.

Ethics approval The study was approved by the Research ethics committee of the Faculty of Medicine (09/2020) and the use of health register data by the Finnish Institute for Health and Welfare (THL/1538/5.05.00/2019).

Provenance and peer review Not commissioned; externally peer reviewed.

Data availability statement Data may be obtained from a third party and are not publicly available. Deidentified data may be available from the corresponding register keepers on reasonable request but are not publicly available.

Open access This is an open access article distributed in accordance with the Creative Commons Attribution Non Commercial (CC BY-NC 4.0) license, which permits others to distribute, remix, adapt, build upon this work non-commercially, and license their derivative works on different terms, provided the original work is properly cited, appropriate credit is given, any changes made indicated, and the use is non-commercial. See: http://creativecommons.org/licenses/by-nc/4.0/.

ORCID iD

Eerika Jalanko http://orcid.org/0000-0001-5761-7069

\section{REFERENCES}

1 Sedgh G, Finer LB, Bankole A, et al. Adolescent pregnancy, birth, and abortion rates across countries: levels and recent trends. $J$ Adolesc Health 2015;56:223-30.

2 Hognert H, Skjeldestad FE, Gemzell-Danielsson K, et al. Ecological study on the use of hormonal contraception, abortions and births among teenagers in the Nordic countries. BMJ Open 2018;8:e022473.

3 Lindberg L, Santelli J, Desai S. Understanding the decline in adolescent fertility in the United States, 2007-2012. J Adolesc Health 2016;59:577-83.

4 Leppälahti S, Gissler M, Mentula M, et al. Is teenage pregnancy an obstetric risk in a welfare society? A population-based study in Finland, from 2006 to 2011. BMJ Open 2013;3:e003225.

5 Maslowsky J, Powers D, Hendrick CE, et al. County-Level clustering and characteristics of repeat versus first teen births in the United States, 2015-2017. J Adolesc Health 2019;65:674-80.

6 Leppälahti S, Heikinheimo O, Kalliala I, et al. Is underage abortion associated with adverse outcomes in early adulthood? A longitudinal birth cohort study up to 25 years of age. Hum Reprod 2016;31:2142-9.

7 Jalanko $E$, Leppälahti S, Heikinheimo $O$, et al. The risk of psychiatric morbidity following teenage induced abortion and childbirth-a longitudinal study from Finland. J Adolesc Health 2020;66:345-51.

8 Lindh I, Hognert $\mathrm{H}$, Milsom I. The changing pattern of contraceptive use and pregnancies in four generations of young women. Acta Obstet Gynecol Scand 2016;95:1264-72.

9 Winner B, Peipert JF, Zhao Q, et al. Effectiveness of long-acting reversible contraception. N Engl J Med 2012;366:1998-2007. 
10 Ethier KA, Dittus PJ, DeRosa CJ, et al. School-Based health center access, reproductive health care, and contraceptive use among sexually experienced high school students. J Adolesc Health 2011;48:562-5.

11 Secura GM, Madden T, McNicholas C, et al. Provision of no-cost, long-acting contraception and teenage pregnancy. $N$ Engl J Med 2014;371:1316-23.

12 Peipert JF, Madden T, Allsworth JE, et al. Preventing unintended pregnancies by providing no-cost contraception. Obstet Gynecol 2012;120:1291-7.

13 Gyllenberg F, Juselius M, Gissler M, et al. Long-Acting reversible contraception free of charge, method initiation, and abortion rates in Finland. Am J Public Health 2018;108:538-43.

14 Kirby DB, Laris BA, Rolleri LA. Sex and HIV education programs: their impact on sexual behaviors of young people throughout the world. J Adolesc Health 2007;40:206-17.

15 Green J, Oman RF, Vesely SK, et al. Beyond the effects of comprehensive sexuality education: the significant prospective effects of youth assets on contraceptive behaviors. J Adolesc Health 2017;61:678-84.

16 Foster DG, Biggs MA, Phillips KA, et al. Potential public sector cost-savings from over-the-counter access to oral contraceptives. Contraception 2015;91:373-9.

17 Williams RL, Meredith AH, Ott MA. Expanding adolescent access to hormonal contraception: an update on over-the-counter, pharmacist prescribing, and web-based telehealth approaches. Curr Opin Obstet Gynecol 2018;30:458-64.

18 Mulligan K. Access to emergency contraception and its impact on fertility and sexual behavior. Health Econ 2016;25:455-69.

19 Girma S, Paton D. The impact of emergency birth control on teen pregnancy and STIs. J Health Econ 2011;30:373-80.
20 Primary health care act [online]. Available: httpswww.finlex. fifilakialkup [Accessed 24 Feb 2020].

21 Heino A, Niinimäki M, Mentula M, et al. How reliable are health registers? registration of induced abortions and sterilizations in Finland. Inform Health Soc Care 2018;43:310-9.

22 Gissler M, Teperi J, Hemminki E, et al. Data quality after restructuring a national medical registry. Scand J Soc Med 1995;23:75-80.

23 Glasier AF, Cameron ST, Fine PM, et al. Ulipristal acetate versus levonorgestrel for emergency contraception: a randomised noninferiority trial and meta-analysis. Lancet 2010;375:555-62.

24 Glasier A. The rationale for use of Ulipristal acetate as first line in emergency contraception: biological and clinical evidence. Gynecol Endocrinol 2014;30:688-90.

25 Hoopes AJ, Gilmore K, Cady J, et al. A qualitative study of factors that influence contraceptive choice among adolescent school-based health center patients. J Pediatr Adolesc Gynecol 2016;29:259-64.

26 Gilmore K, Hoopes AJ, Cady J, et al. Providing long-acting reversible contraception services in Seattle school-based health centers: key themes for facilitating implementation. J Adolesc Health 2015:56:658-65.

27 Kavanaugh ML, Jerman J, Ethier K, et al. Meeting the contraceptive needs of teens and young adults: youth-friendly and long-acting reversible contraceptive services in U.S. family planning facilities. $J$ Adolesc Health 2013;52:284-92.

28 The Finnish Institute for Health and Welfare. Medical birth register. unpublished statistics.

29 Wellings K, Jones KG, Mercer CH, et al. The prevalence of unplanned pregnancy and associated factors in Britain: findings from the third national survey of sexual attitudes and lifestyles (Natsal-3). Lancet 2013;382:1807-16 